\title{
ENERGIA EÓLICA E IMPACTOS AMBIENTAIS: UM ESTUDO DE REVISÃO
}

\author{
João Paulo Minardi de Azevedo' \\ Raphael Santos do Nascimento ${ }^{2}$ \\ Igor Bertolino Schram ${ }^{3}$
}

\begin{abstract}
Resumo: A energia eólica é cada vez mais utilizada em todo o mundo como uma importante contribuição para a energia renovável. Entretanto os países de interesse estão preocupados com seus respectivos impactos ambientais. Assim, com a finalidade de contribuir com a discussão sobre este tema, o presente estudo teve como objetivo analisar o uso da energia eólica como fonte renovável e limpa, e apresentar o seu respectivo potencial gerador, podendo ser ela uma alternativa energética e grande aliada no combate a emissão de gases do efeito estufa. Assim concluiu-se neste estudo que a energia eólica tem um futuro ainda mais promissor com a conscientização pública das suas vantagens como fonte renovável e progressiva competitividade econômica. Contudo mesmo apresentando, como toda tecnologia energética apresenta, algumas características ambientais desfavoráveis, conforme visto neste trabalho, 0 aproveitamento dos ventos para geração de energia elétrica deve ser encorajado e algumas destas características podem ser significativamente minimizadas e até mesmo eliminadas com planejamento adequado e inovações tecnológicas.
\end{abstract}

Palavras-chave: Energia eólica; Efeito estufa; Energia renovável; Impactos ambientais.

\footnotetext{
${ }^{1}$ Engenharia Elétrica/Centro Universitário Ingá - Uningá, Brasil. E-mail: joaominardi@hotmail.com.

2 Engenharia Elétrica/Centro Universitário Ingá - Uningá, Brasil. E-mail raphael_caixa@hotmail.com

3 Engenharia Elétrica/Centro Universitário Ingá - Uningá, Brasil. E-mail: prof.igorschram@uninga.edu.br.
} 